International Journal of Management Science

and Business Administration

Volume 2, Issue 12, November 2016, Pages 45-52

DOI: $10.18775 /$ ijmsba.1849-5664-5419.2014.212.1005

URL: http://dx.doi.org/10.18775/ijmsba.1849-5664-5419.2014.212.1005

\title{
A Support of Independent Processes Outside of Information System, Using an Ontology Driven Application
}

\author{
Ladislav Burita \\ Department of Industrial Engineering and Information Systems, Tomas Bata University in Zlín and \\ Communication and Information Systems Department, University of Defence in Brno \\ Svazna Street, Brno, Czech Republic
}

\begin{abstract}
The purpose of the article is to analyze support of the independent processes, using any tool of information technology (IT) outside of the information system (IS) in the enterprise environment. The useful tool of IT could be the software (SW) ATOM, an ontology-driven web based application. Changes in IS are very expensive, complicated and risky, but it should be suggested solution omitted. The extensive literature review of the current state of the topic is added. The chosen process is innovation; the life cycle of innovation is explained: suggestion of innovation, demand for the solution of innovation, the final solution of innovation, and project for implementation of innovation. The methodology of an ontology preparation for the SW application includes design scheme of classes and associations between classes, preparation table of assignment characteristics to classes, and implementation of an ontology design in SW ATOM. The real possibility to support independent processes outside of IS using an ontology-driven application was experimentally verified and confirmed, and the result of research work could be used for any process outside of IS. Limits of the proposed solution consist of only experimental laboratory verification. For the practical use, it should be necessary first to prepare a prototype for the corporation IS in an enterprise environment.
\end{abstract}

Keywords: Information system, Independent process, Innovation, Ontology-driven application, ATOM.

\section{Introduction}

The article is focused on the information technology (IT) support of processes outside of information system (IS) in corporate environment. It is well known that it is time-consuming and costly to set up an IS's missing features, in addition to implementing them on the level of a particular customer. One of the ways to avoid having to do so is the implementation of an application that supports processes outside of an IS, but that is able to cooperate with the corporate IS.

What is the cause of missing features in the IS? One of them could be the consistent application of the "lean" principle that is oriented on eliminating waste, adding value, orientating towards the customer, reducing cost, improving quality, improving continuously, and reducing delivery times. The ultimate goal is to provide perfect value to the customer through a perfect value creation process that has zero waste. To accomplish this, lean thinking changes the focus of management from optimizing separate technologies, assets, and vertical departments to optimizing the flow of products and services through entire value streams that flow horizontally across technologies, assets, and departments to customers.

Eliminating waste along entire value streams, instead of at isolated points, creates processes that need less human effort, less space, less capital, and less time to make products and services with far fewer costs and defects, compared with traditional business systems. Companies are able to respond to changing customer desires with high variety, high quality, low cost, and very fast throughput times. Furthermore, information management becomes much simpler and more accurate (Dudbridge, 2011). 
It is presented a solution to support business innovation process outside of IS based on ontology-driven software (SW) ATOM. The steps of innovation life cycle are mentioned and ontology preparation and knowledge base is explained. The same procedure can be applied for any process outside of IS.

\section{The current state of the research topic}

The paper deals with the support of processes outside of the IS, using a knowledge management system (KMS) in the area of innovation in production company. The topic is quite original as a scientific problem, but there is some papers (Petr, 2013) and companies (Software602, 2016) that offer a technical solution.

The knowledge approach and KMS are mentioned in many sources. The result of analysis knowledge management in Czech companies (Marešová, 2004) stated that: "The Czech companies are interested in knowledge management, but they come across many obstacles, which finally discourage them from its consistent implementation. Within the horizon of three years, companies plan to deal with knowledge management much more intensively and even to remove potential barriers of its introduction. On the whole, it can be stated that companies consider knowledge management as a significant tool for increasing their competitive ability".

Paper (Yang \& Pai, 2004) suggested an improvement of the ineffective administration processes using the userfriendly IS. "Each organization should create the technology and knowledge of administration in order to gain the competitive advantage". The process-oriented knowledge management in product lifecycle is mentioned in the paper (Felic, Koenig-Ries \& Klein, 2014): "To deal with comprehensible knowledge throughout the product lifecycle phases and thereby eliminate communication overhead, this paper presents a process-oriented and integrated semantic solution that supports interoperability of knowledge during all phases of the product lifecycle. Based on shared ontologies and product models, collaborators of product chains have the ability to define their own extensions to the underlying models and ontologies".

The knowledge management approach in loosely coupled systems is analysed in paper (Agrez \& Damij, 2016): "The solution is appropriate for implementation to analyse knowledge network and process architecture relations in different informal organizational networks, as well as during events where spontaneous cooperation among different types of organizations and individuals is necessary, such as massive natural disasters and other similarly events ". Information system is a topic from various point of view in Thousands of scientific papers. „The concept of enterprise systems designed to support the functionality of enterprise has a significant step toward in the long history of technology assisted business process integration. The radical transformation of economic environment forced to elaborate new business models and tightly aligned information technology. At present we are witnesses to and active participants of a new paradigm shift. On the business side the agility and flexibility are the key features. On the information technology side are two emerging approaches: service oriented architecture and business process management "(Lorinz, 2007).

The efficiency of IS regarding support of business processes is presented in theoretical model (Gebauer \& Schober, 2006): „We present a theoretical model that details the economics of two generic strategies of IS flexibility (i.e., flexibility-to-use regarding the IS features that are provided at the time of implementation, and flexibility-to-change regarding the IS features that constitute an option for later system upgrade), and that also includes the possibility of process performance outside of the IS (manual operations). Based on an analysis of the model, we conclude that IS flexibility-to-change is cost efficiently deployed to support a business process characterized by a high level of structural and environmental uncertainty, whereas a low level of process uncertainty corresponds efficiently with IS flexibility-to-use. The model also indicates that high process variability can improve the importance of IS flexibility management in general, as it tends to limit the value of an IS over manual operations, whereas a high level of timecriticality of process requirements tends to increase the value of an IS over manual operations “.

The IS integration and support of processes in the enterprise should be accomplished in portal solution (Lungu, 2009): „Portal SW continues to offer one of the few infrastructure frameworks that truly embrace open and flexible computing. A portal is a point of integration, useful to the organization by integrating internal business processes and by offering information to the outside world. We can use portals in decision making in two ways. One way is, by enabling managers to access the data they require by using the portal's interface. Another way, which doesn't exclude the first is, by developing a distinct decision support application within the portal which uses scenarios using the data from the integrated systems to help managers make more well-founded actions ". 
The topic of innovation in enterprise is analysed from the competitiveness point of view (Atzei, 1999), where is reason for innovation found in aspects: "The adaptations of industrial and public organizations to the global market needs; the understanding of the bottleneck factors limiting competitiveness; the trends toward new system architectures and new engineering and production methods; the understanding of the role of new technology in the future applications ".

The innovation mechanism as a business management tool is described in the paper (Guanzhong, 2011): "Entrepreneurial activity is a spiralling cycle process, its essence lies in the integration of resource production and deployment through management innovation. That realizing the proliferation of business value continuously in whole running process of enterprise, becomes the second core competencies. Aims at adjusting the national industrial structure and changing the mode of economic growth, the paper advocates to classify the enterprises according to 3 factors as manufacturing strategy level, value growth mode and developing stage of enterprises, summarized the commonality of design innovation in different types of enterprises; it is also a new ruler for measuring the enterprises' state of economic development and strategic transformation. The way enterprises engaged in creative design activities is closely related to the type of businesses, the mechanisms of innovative design will be restricted and affected by the environmental conditions within and outside the enterprise. We will analyze the innovative mechanisms and content from internal and external sides “.

The KMS for innovation is presented in the paper (Waris, Sanin \& Szczerbicki, 2016): "Knowledge and experience are essential requirements for product innovation. It is proposed a systematic approach for product innovation support using a KMS comprising a Set of Experience Knowledge Structure and Decisional DNA. This proposed system is dynamic in nature because it updates itself every time a new decision related to innovation is made. Through this system, the product innovation process can be performed semi automatically and efficiently because it stores knowledge of past experiences of innovative decisions“.

\section{Support of processes outside the IS}

In business practice, it is apparent that some processes need to be supported by the IS more urgently, but they also need to maintain the independence of the systems. Without this, the organization fails to be sufficiently flexible and its processes cannot be sufficiently distinguished from those of competitors working with the same system. A suitable solution is an application capable of exchanging data with IS. This is actually a fairly common situation. A larger organization with many ISs (such as a bank) sees a new opportunity in the market and wants to introduce a new product. Working out exactly what the product has to contain and to whom it should be offered may not take more than a few days, but then ICT becomes involved. It is necessary to carry out interventions in the customer system, in the central transaction system, in the internal product catalogue, in which are working partners, and in several other systems. It is therefore necessary to convene architects, process consultants, security specialists, administrators of the systems, and infrastructure specialists.

They assess the risk ("we do not want to risk that, because the changes will mean limited support for the existing products") and a project starts to take shape that takes more than half a year and will require a budget stretching to millions. Do we really want to introduce the new product? Can the project be defended to the board? Now try and imagine that it would be possible to produce the same products, taking a few days, without interfering with the individual systems. There is no need for discussions with architects and security experts. It is not even necessary to process consultants. For a start, they produce a preliminary definition of the process, and only if it is shown that the product is really interesting it would be appropriate to devote efforts to fine-tuning the processes and ICT support.

Medium-sized companies solve different problems from banks and they operate different infrastructures, but their situation is in some respects similar. If they want to process the customers' needs, they may run into a similar problem even within a single information system. This is especially the case of the expensive and complex enterprise resource planning systems. The processes in the system are set up according to best practices, and if an organization wants to act differently from most, it will need special treatment, involving very long and thorough testing.

Otherwise, it will run the risk that somewhere in another part of the system a change will occur in unpredictable settings. Thus, again, the process of the IS implies the end of flexibility. However, apart from the tailored SW, there is other (cheaper and easier) solution, even for standard IS - the utilization of an application. There is a solution that 
facilitates the management of processes outside the IS. The requirements that have to be fulfilled by the applications are: "Cooperation with IS (loading data from them and passing the results back); the workflow process that delivers the right information at the right time to the right person; a user-friendly interface; and creating and archiving documents" (Petr, 2013).

\section{Innovation in the enterprise}

Innovation is obviously one of the key business processes that drive success. The principle that innovation must be a core element of every organization's strategy is a primary management rule. To create a realistic possibility of breakthroughs and new business model innovations, and to improve the quality of everyone's ideas of all types, incremental, breakthrough, and business model, it is necessary to structure the process in a much more purposeful way. Just in case you think that success is a question of how much money you spend, please think again. Recent studies show that success in innovation is not a function of how much is spent on research and development, but rather on the quality of the process. Innovation development is design and engineering to transform great concepts into finished products, services, and business designs. This should be an integrated, multi-disciplinary process that includes the researchers, who still probably understand the ideas best, because they have already carried out so much work on them, as well as people with deep knowledge of the relevant business domains, which may include manufacturing, distribution, branding, marketing, and sales. Project management skills are very important here. It is often at the project management stage that the existence of the innovation is disclosed to customers in the ongoing effort to engage them as innovation partners and to maintain their loyalty in the face of competing offers (Morris, 2011).

Innovation is based on a simple idea that brings something new and different, emotionally. Lasting success has been recorded only by those businesses that have created their own system of governance and with it, after hard and difficult work, achieved success. There must not be a lot of talk about strategic objectives, customer value indicators, metrics, resource allocation, priorities, and development plans. More natural human contact, more entrepreneurship, enthusiasm for the cause, freedom, and self-realization are important elements of innovation. Growth based on innovation rises on existing values and new markets. Areas include innovative products and services, as well as key processes and business systems (Košturiak \& Chal', 2013).

Scott (2013) warns against boundless innovation development. It is necessary to provide initial innovation requirements for the development of a market, the definition of a financial framework, and a substantive limitations solution and its outcome. Although such restrictions may limit the number of innovative options, any reasonable restriction promotes creative thinking and prevents time wasting on something that could well be rejected by the management.

\subsection{The life cycle of innovation}

With respect to the result of literature review and its analysis, is an innovation process for the research experiment divided into 4 phases:

1. The suggestion of innovation.

2. Demand for innovation.

3. The result of innovation.

4. Project of implementation.

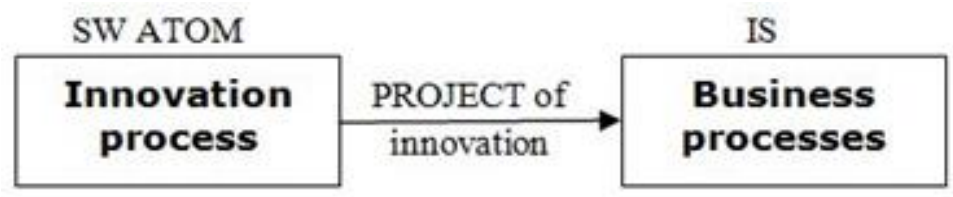

Figure 1: Cooperation between SW ATOM and information system

Phase suggestion of innovation (SI) is opened for all employees of a company, insertion of the SI is simple, and the related form is generated from the ontology automatic. In the demand for innovation (DI) phase is innovation an object of evaluation of company managers and department that is goal of DI. The DI is completed with limitations of the innovation and with other requirements of the solution. If a DI is accepted than can be solved and successful result will be added to the phase result of innovation (RI) and then is converted into project of implementation (PI) phase and data 
is translated into IS. Innovation process is supported by application in SW ATOM (2016) and the result of solution of innovation is translated into IS, where is processed, see Figure 1.

\section{Ontology definition and preparation base of innovations}

Ontology is a heart of the application in SW ATOM; it defines structure of the knowledge in the area of interest; includes classes, associations between classes, characteristics of classes; and occurrences of classes and associations. The methodology steps of ontology development are:

1. Schema of classes and associations, prepared using VUE (2016), see Figure 2.

2. Table of assignment characteristics to classes, see Table 1.

3. Ontology implementation in SW ATOM, see Figure 3.

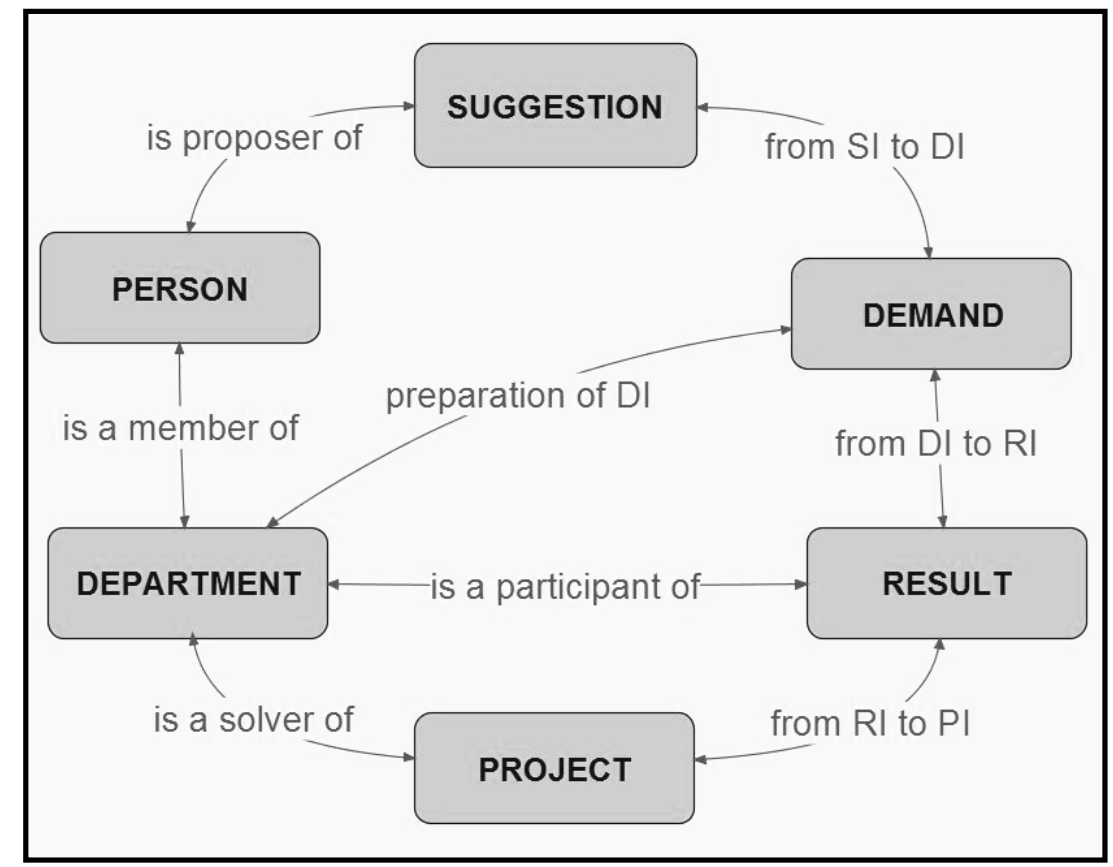

Figure 2: Schema of ontology classes and associations

Ontology classes include (see Figure 3): PERSON (PER) - that suggested or solved innovation, DEPARTMENT (DEP) - department of person and guarantor of solution of innovation; SUGGESTION - the primary suggestion of innovation, as an activity of employees.

Table 1: Table of assignment characteristics to classes

\begin{tabular}{|r|l|l|l|l|l|l|l|l||}
\hline ORD & CHARACTERISTIC/CLASS & DATA TYPE & DEP & PER & SI & DI & RI & PI \\
\hline 1 & Benefit & Number & & & $\mathbf{X}$ & $\mathbf{X}$ & $\mathbf{X}$ & $\mathbf{X}$ \\
\hline 2 & Date of decision & Date & & & $\mathbf{X}$ & $\mathbf{X}$ & $\mathbf{X}$ & \\
\hline 3 & Date of proposal & Date & & & $\mathbf{X}$ & $\mathbf{X}$ & $\mathbf{X}$ & \\
\hline 4 & Date of start & Date & & & $\mathbf{X}$ & $\mathbf{X}$ & $\mathbf{X}$ & $\mathbf{X}$ \\
\hline 5 & Date of termination & Date & & & $\mathbf{X}$ & $\mathbf{X}$ & $\mathbf{X}$ & $\mathbf{X}$ \\
\hline 6 & Function & Text & $\mathbf{X}$ & $\mathbf{X}$ & $\mathbf{X}$ & $\mathbf{X}$ & $\mathbf{X}$ & $\mathbf{X}$ \\
\hline 7 & Limitation - factual & Text & & & & $\mathbf{X}$ & $\mathbf{X}$ & $\mathbf{X}$ \\
\hline 8 & Limitation - financial & Number & & & & $\mathbf{X}$ & $\mathbf{X}$ & $\mathbf{X}$ \\
\hline 9 & Name or Title & Name & $\mathbf{X}$ & $\mathbf{X}$ & $\mathbf{X}$ & $\mathbf{X}$ & $\mathbf{X}$ & $\mathbf{X}$ \\
\hline 10 & Objectives of solution & Text & & & $\mathbf{X}$ & $\mathbf{X}$ & $\mathbf{X}$ & $\mathbf{X}$ \\
\hline 11 & Outputs of solution & Text & & & $\mathbf{X}$ & $\mathbf{X}$ & $\mathbf{X}$ & $\mathbf{X}$ \\
\hline 12 & Sources - factual & Text & & & & $\mathbf{X}$ & $\mathbf{X}$ & $\mathbf{X}$ \\
\hline 13 & Sources - financial & Number & & & & $\mathbf{X}$ & $\mathbf{X}$ & $\mathbf{X}$ \\
\hline 14 & Status & Group-tree & & & & $\mathbf{X}$ & $\mathbf{X}$ & $\mathbf{X}$ \\
\hline 15 & WWW page & URL & $\mathbf{X}$ & $\mathbf{X}$ & & & & \\
\hline \hline
\end{tabular}




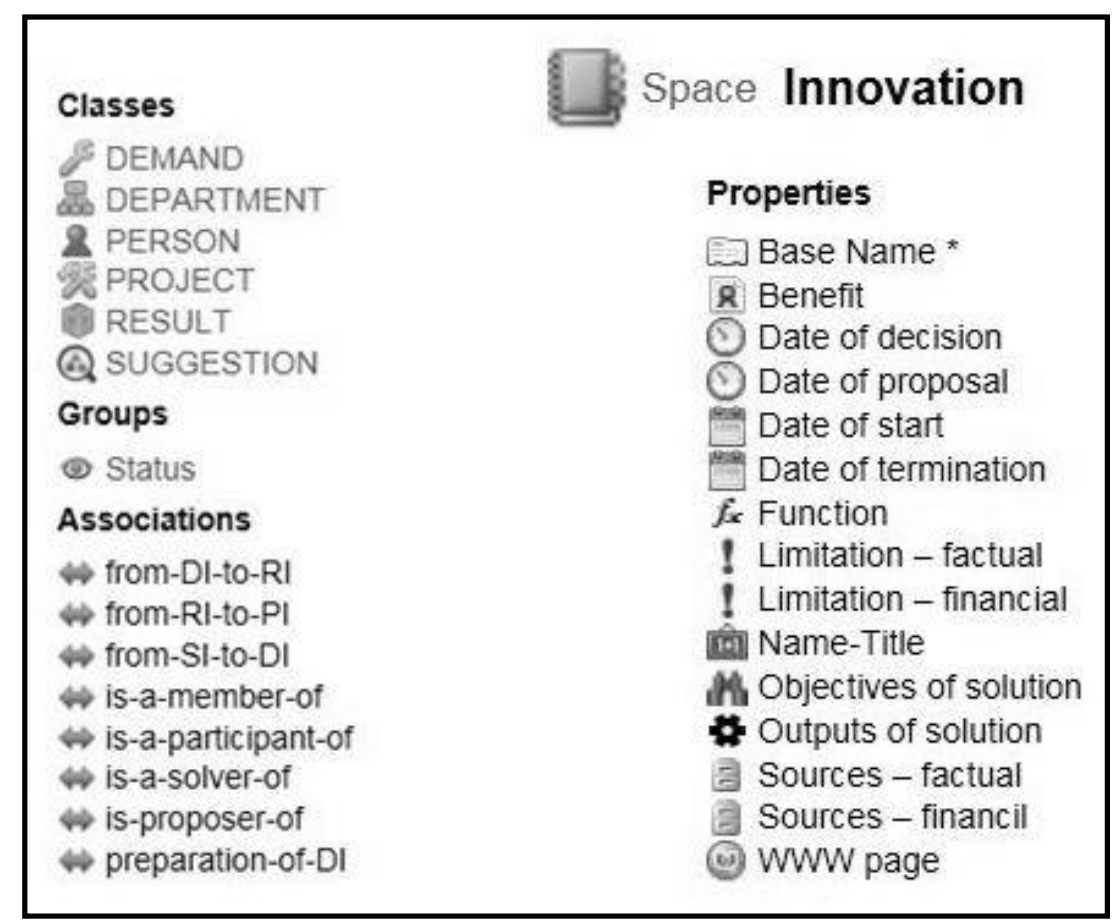

Figure 3: Ontology definition in SW ATOM

The suggestion is evaluated by senior management of a company and if fits to the goals of company is released for solution of innovation as a DEMAND. The class RESULT is a result of solution of innovation and is converted to PROJECT for implementation. The knowledge base of innovations is prepared using automatic generated forms from ontology by including occurrences of classes and setting up associations between them.

The innovation is written into the standard form; see Figure 4. In the form, the innovation is connected to the proposal person or department of challengers and the department towards which the innovation is oriented is selected. A list of saved suggestions of innovations is shown in Figure 5. The experiment shows that the application works quite reliably, is easily manageable by users, and fulfil the necessary requirements.

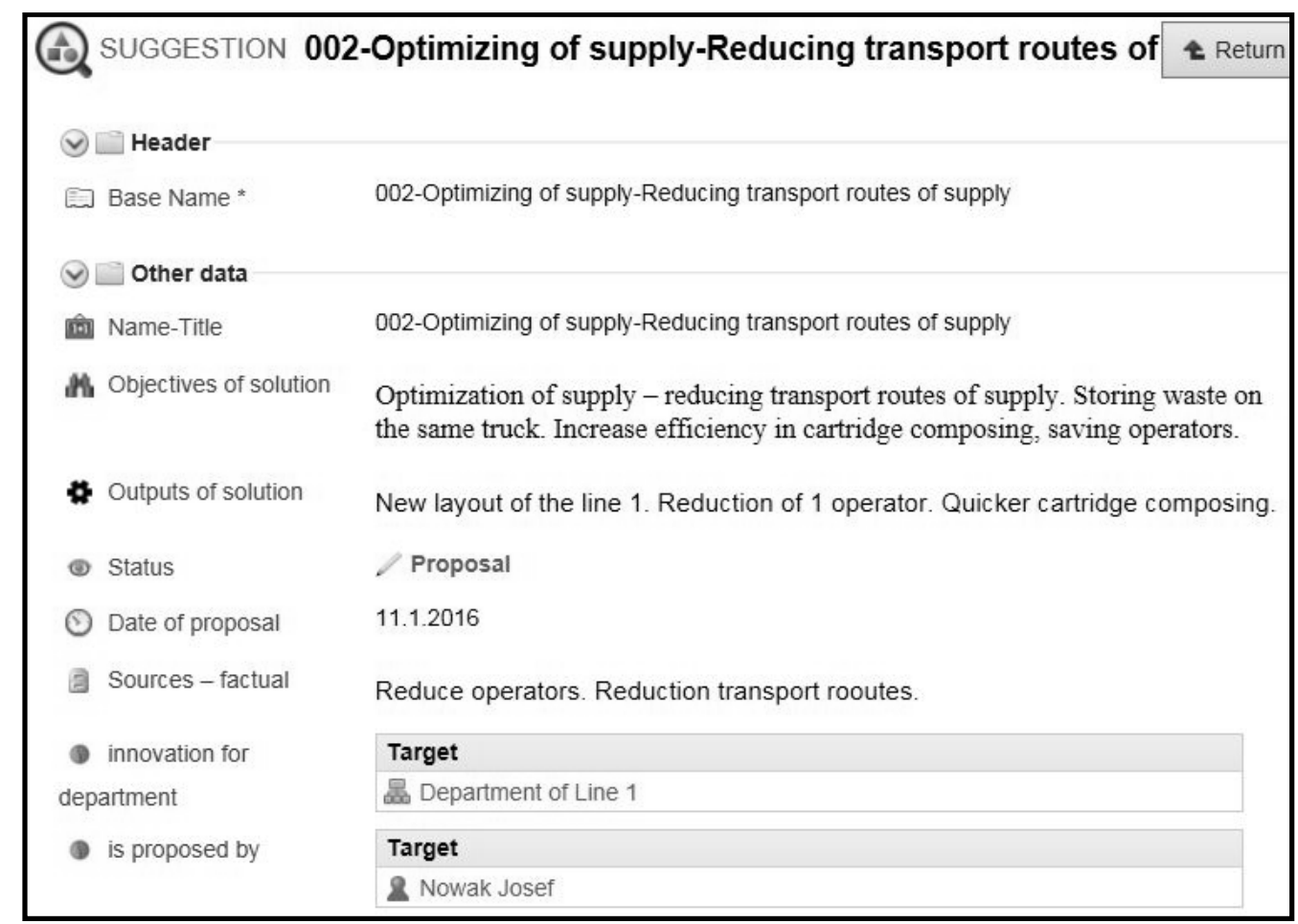

Figure 4: Form for including suggestion of innovation 


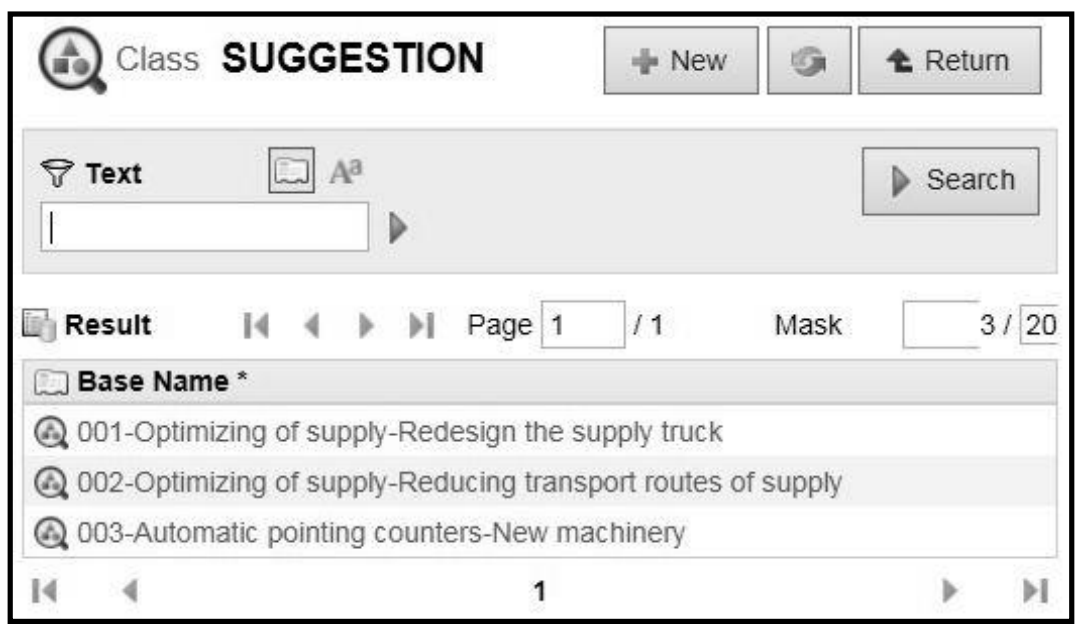

Figure 5: List of suggestions for innovation

\section{Discussion and proposal for further research}

The paper presents the results of the initial phase of the project, in which a possible problem of information support for a lean enterprise was specified. Based on the experience of the research in knowledge systems, a solution to the specified problem has been proposed. However, the potential implementation of ATOM in enterprise practice for support of processes outside IS will require time.

First, it is necessary to conduct the analytical and experimental phase of the project, which will select a process that is not supported by an IS, and to verify experimentally in an enterprise environment whether ATOM, as its characteristics show, is able to run successfully in the form of an application with chosen process. If the answer is yes, then it is necessary to verify it in a real case in enterprise practice as a prototype in the synthetic phase of a project. Only then the results of the experiment can be generalized and methodically closed. The advantage of the ontologically driven system ATOM is that an arbitrary missing function of an IS can be supported.

\section{Conclusion}

The article presents results of research in support of processes outside of a corporate IS. The reason of the missing functions in an IS could be, for example, the consistent application of the "lean" principle that is oriented on eliminating waste and reducing cost. The missing function of an IS is in the research an innovation process. The life cycle of innovation in an enterprise is explained. The application that supports innovation process outside of IS is prepared using SW ATOM. Methodology of the implementation of application is presented; its core task is an ontology preparation. Base of data is included using form that is automatic generated from ontology.

The experiment with the support of the process of innovation outside of IS sufficiently confirms the conformity of the procedure. But this is only a laboratory environment. For the corporate environment, should be necessary next research phase: development of a prototype that verifies the laboratory result.

The article recommends one of the possible candidates for an application SW ATOM, and presents an example of its implementation as a knowledge system in innovation process support. To put it into practice, it is necessary to take a number of steps, which pose a challenge to our future research activities.

\section{References}

- Agrez, J., \&Damij, N. (2016). A knowledge management approach to the loosely coupled systems. Information Resources Management Journal, 29(1), 75-90, CrossRef

- ATOM. (2016). Aion Topic Maps Engine. Retrieved from http://www.aion.cz/.

- Atzei, A., Groepper, P., \&Novara, M. et al. (1999). Innovations for competitiveness: European views on "better-faster-cheaper". Actaastronautica, 44(7-12, Special Issue), 745-754, CrossRef 
- Dudbridge, M. (2011). Handbook of Lean Manufacturing in the Food Industry. UK: Blackwell Publishing, CrossRef

- Felic, A., Koenig-Ries, B., \&Klein, M. (2014). Process-Oriented Semantic Knowledge Management in Product Lifecycle Management. In Proceedings of the 8th International Conference on Digital Enterprise Technology. Stuttgart, Germany, 361-368, CrossRef

- Gebauer, J.,\&Schober, F. (2006). Information system flexibility and the cost efficiency of business processes. Journal of the association for information systems, 7(3), 122-147.

- Guanzhong, L. (2011). Embedding "Design Innovative Mechanisms" Is the Top Priority of Business Management. In Proceedings of the 4th International Conference on Mechanical Engineering and Mechanics. Suzhou, China, 894-901.

- Košturiak, J., \&Chal', J. (2013) Inovácie: stručne a prakticky (Innovation: simple andpractise). Žilina, IPA Slovakia. Retrieved from http://www.krajciova.sk/_dokumenty/informacie/07_KCH_Inovacie_MK.pdf

- Lungu, I., Velicanu, M., \&Bara, A. et al. (2009). Portal based system integration - foundation for decision support. Economic computation and economic cybernetics studies and research, 43(1), 123-134.

- Lorincz, P. (2007). Evolution of Enterprise Systems. In Proceedings of the International Symposium on Logistics and Industrial Informatics Location. Wildau, Germany, 64-69, CrossRef

- Marešová, P. (2010). Výzkumuplatněníznalostníhomanagementu v českýchpodnicích (Survey of knowledge management in Czech companies). E+M Ekonomie a management, 10(1), 131-140.

- Morris, L. (2011). The Innovation Master Plan. Retrieved from http://innovationmanagement.se/wpcontent/uploads/2011/08/Innovation_Master_Plan_Intro.pdf

- Petr, J. (2013). Process management out of the information system. IT Systems,15(9), 16-17.

- Scott, A. (2013). Set Your Innovation Teams on the Right Path. Retrieved from http://blogs.hbr.org/2013/10/set-your-innovation-teams-on-the-right-path/\#disqus_thread

- Software602. (2016). Solution and tools. Retrieved from http://www.602.cz/.

- VUE. (2016). Visual Understanding Environment. Retrieved from http://vue.tufts.edu/

- Waris, M. M., Sanin, C., \&Szczerbicki, E. (2016). Toward Smart Innovation Engineering: Decisional DNABased Conceptual Approach. Cybernetics and Systems, 47(1-2), 149-159, CrossRef

- Yang, CF., \&Pai, CC. (2004). Electronic administration - Knowledge creation and management. In: Proceedings of the 8th World Multi-Conference on Systemic, Cybernetics and Informatics. Orlando, US, 3, $26-43$. 